\title{
SIMULATED CHANGES IN EXTREME RAINFALL OVER SOUTHERN AFRICA
}

\author{
S. J. MASON AND A. M. JOUBERT \\ Climatology Research Group, University of the Witwatersrand, P.O. Wits, 2050, Johannesburg, South Africa \\ email: simon@crg.bpb.wits.ac.3aralec@crg.bpb.wits.ac.uk \\ Received 20 September 1994 \\ Revised 15 June 1996 \\ Accepted 28 June 1996
}

\begin{abstract}
A general circulation model simulation is used to investigate possible changes in rainfall over southern Africa resulting from a doubling of atmospheric carbon dioxide. Simulated increases in rainfall intensity are found to be a spatially coherent and an apparently less regionally dependent signal of climatic change than changes in annual means or number of rain-days. Accordingly, increases in both the frequency and intensity of extreme daily rainfall events are simulated throughout most of the subcontinent. Simulated increases in the intensity of the lowest frequency floods are shown to be particularly severe, suggesting that greenhouse-related climatic change may be most detectable through an increase in extreme flood events rather than changes in long-term means. Similar results are evident when changes in the frequency and intensity of prolonged rainfall events, measured over a period of five consecutive days, are analysed. All results are qualitatively similar to those for the Australian region, except that the model's sensitivity to sharp changes in topography over southern Africa is highlighted.
\end{abstract}

KEY WORDS: climatic change; southern Africa; carbon dioxide; return periods; extreme events; floods

\section{INTRODUCTION}

Much of southern Africa lies within arid or semi-arid climatic regions with the result that water resources in the area are severely limited. Southern Africa also experiences a high degree of interannual rainfall variability, thus compounding the problems of water resource management. The climatic characteristics of high rainfall variability and low annual means combined with a poor level of infrastructural development have resulted in a high vulnerability, particularly of rural communities, to extreme climatic events such as droughts and floods. The impacts of the drought of the early 1980s and of the 1991-1992 drought illustrate the susceptibility of communities in the southern African region to climatic extremes (Vogel and Drummond, 1993; Vogel 1994). At the same time, severe flooding events, such as the floods of September 1987 (Triegaardt et al., 1988) and the February-March floods of 1988 (Lindesay and Jury, 1991), can have equally serious impacts. Given the vulnerability of communities in southern Africa, changes in the frequency and severity of extreme climatic events, resulting from an increase in atmosphere carbon dioxide $\left(\mathrm{CO}_{2}\right)$, could have serious implications.

Climatic changes in response to an enhanced-greenhouse effect traditionally have been considered in terms of possible changes in long-term average conditions, such as changes in mean temperature or rainfall. It is probable, however, that the frequency and intensity of extreme events such as droughts, floods, blizzards or hurricanes, are more sensitive to changes in climate than increases or decreases in climatic means (Mearns et al., 1984; Wigley, 1987; Wigley and Jones, 1987; Katz and Brown, 1992; Katz and Acero, 1994).

An increase in heavy rainfall events may be expected under a doubled $\mathrm{CO}_{2}$ climate because of the sensitivity of atmospheric convection to temperature. The amount of water precipitated from a given vertical column of air over the oceans increases non-linearly with an increase in sea-surface temperatures (Stephens, 1990; Trenberth, 1991; Hartman and Michelsen, 1993; Zhang, 1993). As a result, in regions such as the tropics where warmer seasurface temperatures may be expected under enhanced greenhouse conditions, the percentage increase in precipitable water for given warming may be greater than in higher latitudes (Rind et al., 1989). Over southern

CCC 0899-8418/97/030291-11 \$17.50

(C) 1997 by the Royal Meteorological Society 
Africa, the source of moisture for summer convection is largely oceanic (D'Arberton, 1993) and therefore the increase in available water vapour may be expected to result in an increase of convective rainfall. In addition, given increased condensation of water vapour, the release of latent heat will further strengthen convective activity (Gordon et al., 1992). It has been shown that an increase in atmospheric moisture content is more likely to result in an increase in rain per rain-day rather than in the number of rain-days in many areas of the globe (Fowler and Hennessy, 1995).

Increases in convective activity have been simulated by several modelling groups in enhanced-greenhouse experiments using general circulation models (GCMs) (Noda and Tokioka, 1989; Mearns et al., 1990; Gordon et al., 1992; Mitchell and Ingram, 1992; Whetton et al., 1993). Given an increase in convective activity, changes in the frequency distribution of grid-point daily rainfall totals may be expected (Whetton et al., 1993). The Commonwealth Scientific and Industrial Research Organization (CSIRO) four-level (CSIRO4) and nine-level (CSIRO9) GCMs show qualitatively similar changes in the frequency and intensity of daily rainfall (Gordon et al., 1992; Whetton et al., 1993). Both indicate a general increase in the frequency of high rainfall events and a decrease in the number of rain-days in the mid-latitudes. Less clear changes have been found for other regions using different models, however. Mearns et al. (1990) found greater variability consistent with heavier rainfall events over the USA using the NCAR Community Climate Model. However, Rind et al. (1989), using the GISS GCM, and Wilson and Mitchell (1987), using the low-resolution UKMO model did not find clear changes over the USA and Europe respectively.

The CSIRO9 GCM (McGregor et al., 1993; Whetton et al., 1993) is used here to examine possible changes in the frequency and intensity of extreme daily rainfall events over southern Africa. The changes in rainfall extremes are compared with the simulated changes in rainfall means and average intensities. Broadly, the study extends the investigation of possible implications for changes in extreme rainfall events over Australia (Whetton et al., 1993). Possible changes in the frequency and intensity of droughts over southern Africa are considered in Joubert et al. (1996).

\section{DATA AND METHODS}

Control and doubled- $\mathrm{CO}_{2}$ simulated daily rainfall data by the CSIRO nine-level GCM were obtained from the CSIRO. The atmosphere model is coupled to a simple mixed-layer ocean and a Q-flux correction is applied to ensure accurate representation of seasonally varying sea-surface temperatures. As with its four-level predecessor (Gordon et al., 1992) the model incorporates a modified Arakawa moist-adjustment convection scheme which generates a mass flux. A full description of the model is given in McGregor et al. (1993). Annual totals, average number of rain-days per year (defined according to Whetton et al. (1993) as a day with $0.2 \mathrm{~mm}$ of rainfall or more) and average rainfall intensities were calculated from daily data for each of the 28 model years available at each grid-point representing Africa and the surrounding oceans south of the Equator. The area considered in this paper is illustrated in Figure 1(a) together with a map showing the main topographic features of the subcontinent (Figure 1(b)). It is evident that most of southern Africa consists of a plateau above $1000 \mathrm{~m}$. The statistics of the control climate were compared with observations as a validation to supplement that of Joubert (1995). Percentage changes in average annual rainfall, number of rain-days per year and average rainfall intensity resulting from an increase in atmospheric $\mathrm{CO}_{2}$ were then calculated. The statistical significance of changes in these rainfall characteristics was calculated using a $t$-test.

For both control and perturbed experiments the maximum annual rainfall in each model year, $x_{i}$, at each gridpoint was recorded. Generalized extreme value distributions were then fitted to the annual rainfall maxima at each grid-point. The generalized extreme value (GEV) distribution provides the best fit of the distributions commonly used to describe the frequency distribution of annual rainfall maxima for South African stations (Mason and Mimmack, 1995). The parameters of the distribution were obtained using maximum likelihood estimation and the significance of the fit was tested using the Kolmogorov-Smirnov test.

Daily rainfall magnitudes for $T=5-, 10-, 15-, 20-, 25-$, and 30-year floods were calculated from the fitted GEV distributions for both control and perturbed climates. The percentage change in daily rainfall maxima for a given 


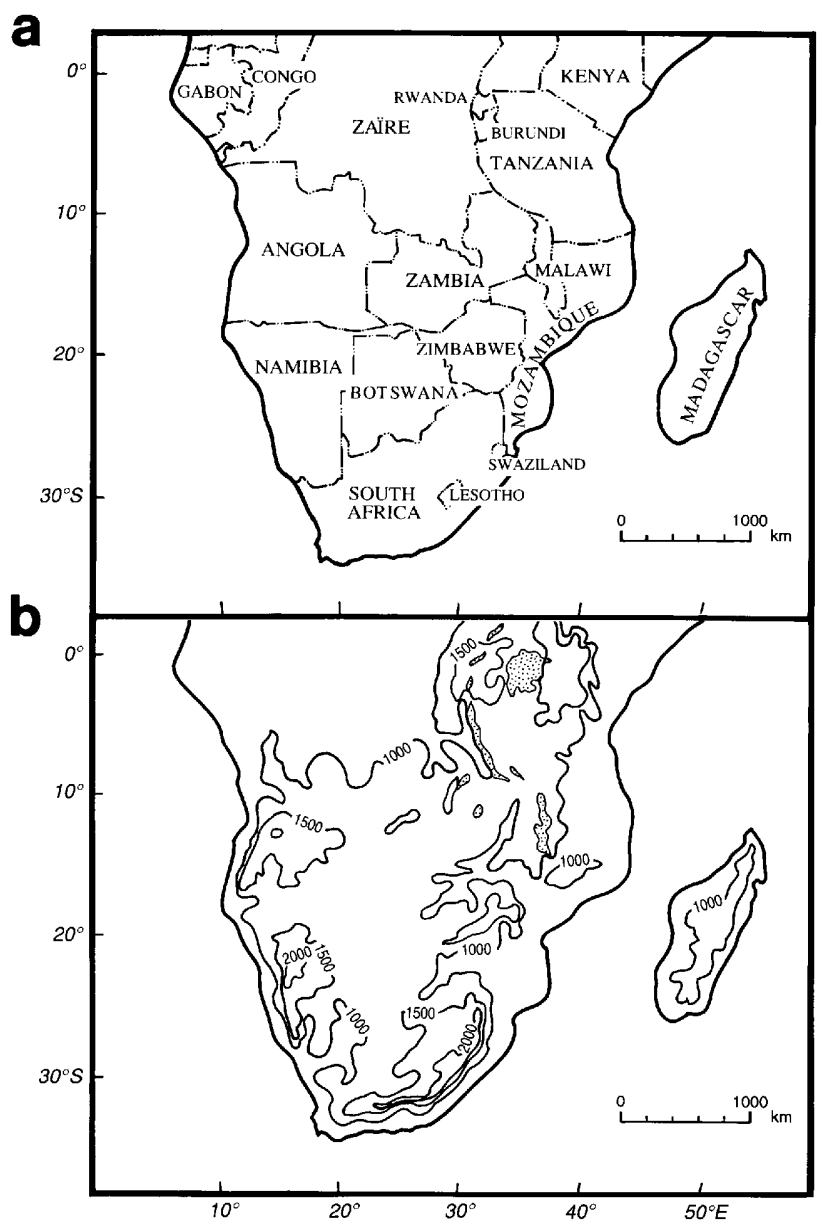

Figure 1. (a) Geopolitical map of Africa south of the Equator. (b) Topographical map of Africa south of the Equator showing contours at 1000, 1500 , and $2000 \mathrm{~m}$

return period, $\mathrm{d} X_{T}$, was then calculated using

$$
\mathrm{d} X_{T}=\left(\frac{G_{2}\left[T^{-1}\right]}{G_{1}\left[T^{-1}\right]}-1\right) \times 100
$$

where $G_{1}$ and $G_{2}$ are the cumulative gamma distribution functions as fitted to the control and perturbed rainfall data respectively. Changes in rainfall magnitudes for the given return periods were calculated in an identical manner for maximum 5-day (pentad) rainfall totals.

\section{MODEL VALIDATION}

Estimating simulated changes in rainfall intensity from general circulation models (GCMs) is recognized as highly problematic (IPCC, 1990, 1992). Whetton et al. (1993) list several causes of uncertainty in predictions of regional patterns of daily rainfall changes. The coarse horizontal and vertical resolution of GCMs results in a crude representation of rainfall processes generally, and particularly in the case of convective rainfall. As a result, predictions of regionally specific rainfall changes can differ significantly between models and for different regions (IPCC, 1992), and has been shown to be the case for southern Africa (Joubert, 1994). Careful validation of control climate output is required therefore. 
The CSIRO9 model provides the best simulation of the rainfall seasonality over southern Africa compared with other GCMs not coupled to an oceanic general circulation model (Joubert, 1995). A validation of the control climate annual mean rainfall against observations has not been performed, however. In Figure 2 the simulated annual mean rainfall (Figure 2(a)) is compared with the observed annual mean (Figure 2(b)) for Africa south of the Equator. Some of the important features of the observed spatial distribution of rainfall are simulated correctly by the model, including the east-west gradient of mean rainfall culminating in the Namib desert of the west coast. The rainfall maximum $(>2000 \mathrm{~mm})$ in near-equatorial central Africa is also reproduced but is about $10^{\circ}$ of latitude too far south in the model simulation. The western part of Angola is too dry in the model, and further south the dry west coast is about three times wetter than observed. Over the eastern half of the subcontinent simulated rainfall is reasonably close to observations except for occasional near-coastal grid-points that produce localized minima and maxima. A near-coastal grid-point on the south coast similarly produces a localized minimum that is not evident in the observational data, except perhaps for a southward extension of the $200 \mathrm{~mm}$ isohyet to about $33^{\circ} \mathrm{S}$ between $20^{\circ} \mathrm{E}$ and $23^{\circ} \mathrm{E}$. With the coarse resolution of the model grid-points the model appears to be highly sensitive to pronounced topography. Along both the south and east coasts of southern Africa changes in altitude of up to $3000 \mathrm{~m}$ over distances considerably less than model resolution (horizontal spectral
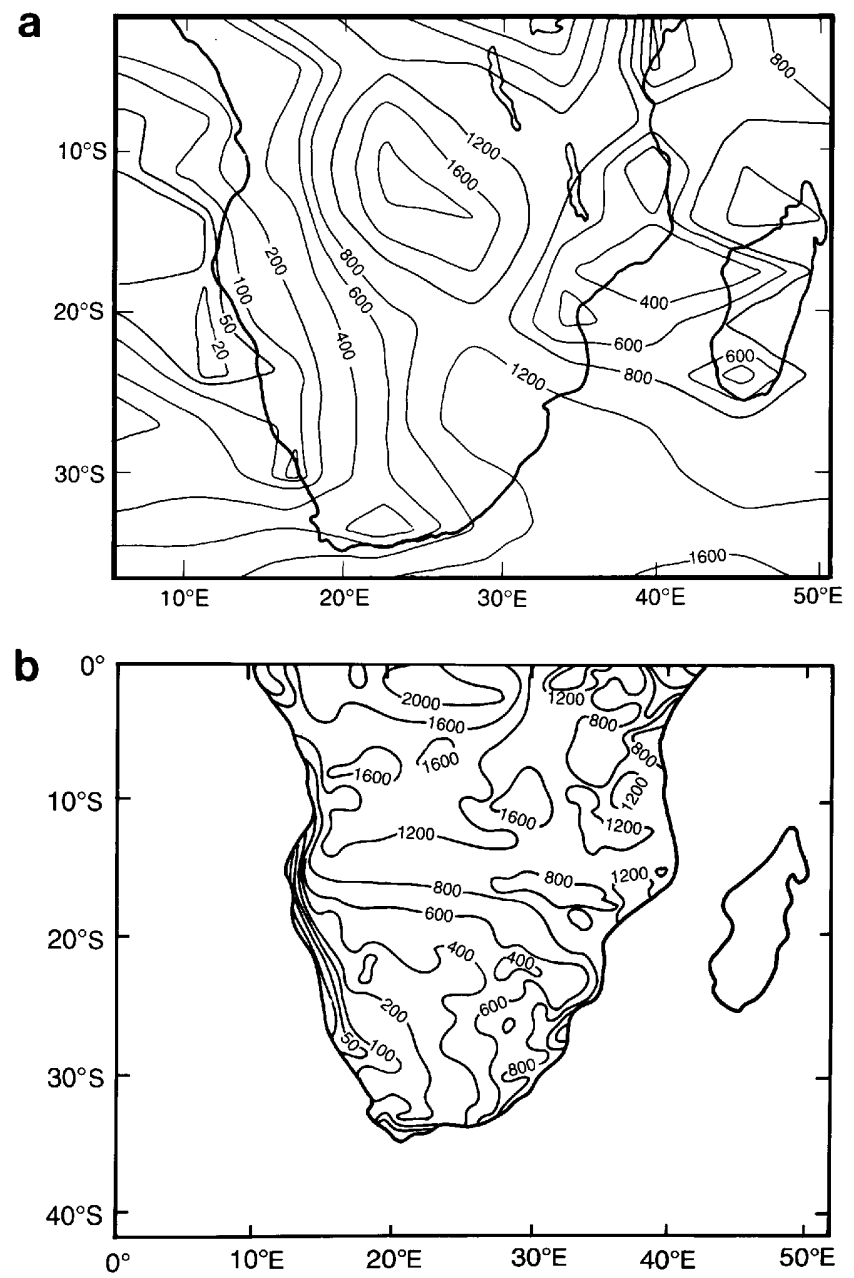

Figure 2. (a) Control $\left(1 \times \mathrm{CO}_{2}\right)$ mean annual rainfall as simulated by CSIRO9. (b) Observed mean annual rainfall (after Nicholson et al., 1988). Units are in millimetres 

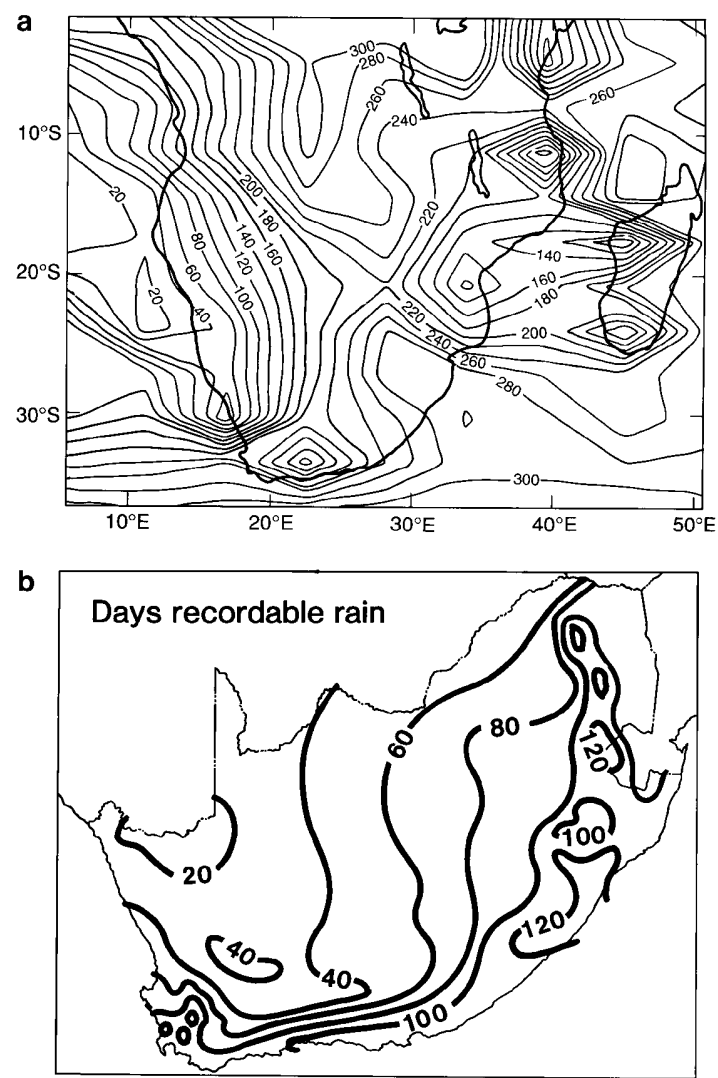

Figure 3. (a) Control $\left(1 \times \mathrm{CO}_{2}\right)$ mean number of rain-days $(\geq 0.2 \mathrm{~mm})$. (b) Observed number of days with recordable rain over South Africa (after Schulze, 1984)

resolution $c a .5 \cdot 6^{\circ}, c a .650 \mathrm{~km}$ ) are evident (Figure $1(\mathrm{~b})$ ). A similar sensitivity to pronounced topography is evident along the east coast of Madagascar.

The model sensitivity to topography is less evident on the west coast but more evident on the east coast of southern Africa in terms of the average number of simulated rain-days per year (Figure 3(a)). Localized minima are evident on the Tanzanian and Kenyan coasts and also on the west coast of Madagascar. A comparison with observations of South Africa (Figure 3(b)) reveals that the model simulation vastly overestimates the number of rain-days, particularly at about $25^{\circ} \mathrm{E}$ where the number of model rain-days is almost four times too high (also bearing in mind that Figure 3(b) illustrates the number of recordable rain-days whereas Figure 3(a) records only the number of days with more than $0.2 \mathrm{~mm}$ ). It is worth noting, however, that grid-point values simulated by the model are, in essence, area-averages for entire model grid-boxes. As such, the model is likely to overestimate the actual number of rain-days recorded for a particular station near a given grid-point (Whetton, pers. comm.). Nonetheless, the model does overestimate the number of rain-days over both southern Africa and Australia.

\section{SIMULATED CHANGES IN RAINFALL OVER SOUTHERN AFRICA}

Simulated changes in mean annual rainfall as a result of a doubling of atmospheric $\mathrm{CO}_{2}$ are shown in Figure $4(\mathrm{a})$. Widespread increases are simulated over much of the southern African landmass and surrounding oceanic areas (Figure 4(a)). Significant changes are evident along the west and east coasts of the subcontinent (increases exceed 300 per cent off the Namibian coast), but these are in areas where it has been shown that the model's performance is poor because of a sensitivity to topography. Significant areas of changes in rainfall are also evident in the 
western half of Angola, but again this is an area where the model's control simulation is poor (Figure 2). Over the interior and most of the eastern part of the subcontinent simulated changes in rainfall are less significant except over central South Africa in Botswana, where increases of over 40 per cent are evident. A decrease of over 30 per cent over northern Mozambique is also worthy of note and should be compared with an almost 40 per cent decline in expected rainfall over the far eastern part of South Africa over the last two decades (Mason, 1996). The

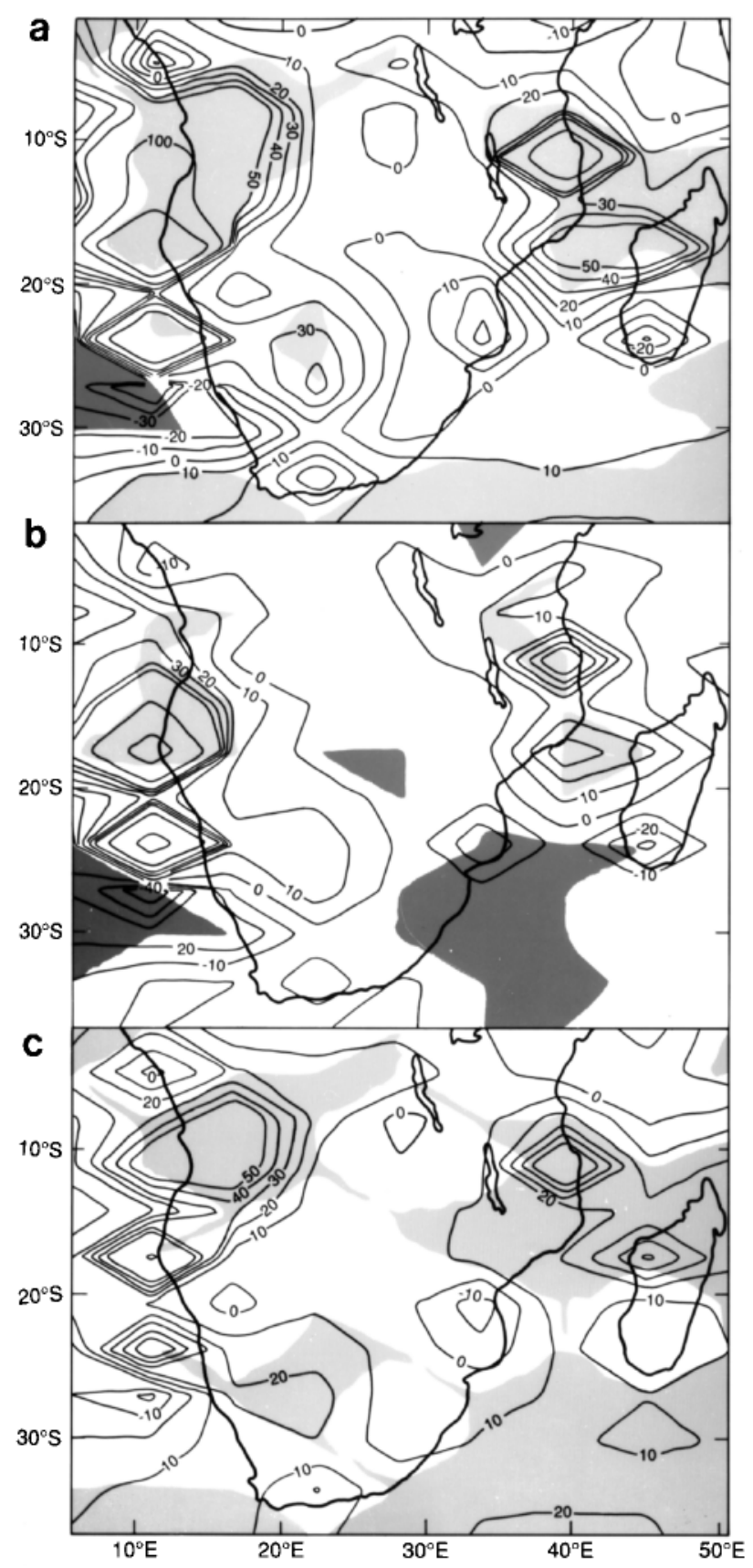

Figure 4. Simulated percentage changes in (a) mean annual rainfall, (b) mean annual number of rain-days ( $\geq 0 \cdot 2 \mathrm{~mm}$ ) and (c) annual mean rain per rain-day. Light stippling indicates areas of significant increase and dark stippling indicates areas of significant decrease (at the 95 per cent significance level) 
east-west contrast in simulated rainfall changes south of $20^{\circ} \mathrm{S}$ may possibly reflect a preference for a more westward alignment of tropical temperate troughs (cf. Harrison, 1984a).

The CSIRO9 model simulates only small changes in the number of rain-days over most of the southern African subcontinent (Figure 4(b)). However, in common with the changes in annual average rainfall, large changes are simulated along the model land-sea boundary. The grid-point-specific changes in the number of rain-days is likely to reflect again a sensitivity in the model to dramatic changes in topography. To the south of the subcontinent, a decrease in the number of rain-days appears to reflect the change in the relative contribution of large-scale and convective rainfall in the mid-latitudes (Gordon et al., 1992; Pittock, 1994).

Given the changes in rainfall amounts and number of rain-days, the model simulates a widespread but small (less than 10 per cent) increase in rainfall intensity (expressed as rain per rain-day) over almost the entire southern African region (Figure 4(c)). Larger increases are evident over the south-western part of the subcontinent south of about $20^{\circ} \mathrm{S}$. The model's sensitivity to large topographic gradients is again indicated in large changes in intensity along both the west and east coasts but the localized minima and maxima are less pronounced.

As was found for the Australian region (Gordon et al., 1992; Whetton et al., 1993), the changes in rainfall intensity over southern Africa provide a more spatially coherent (and apparently less regionally dependent) signal of climatic change than do changes in total rainfall. In both the southern African and Australian regions, the model indicates small increases (between 10 and 20 per cent) in rainfall intensity, even in areas with simulated decreases in annual mean rainfall. This suggests that greater confidence can be expressed in the inter-regional comparability of CSIRO9 simulations of rainfall intensity changes under enhanced-greenhouse conditions (Fowler and Hennessy, 1995).

\section{CHANGES IN EXTREME RAINFALL EVENTS}

\section{Changes in extreme daily rainfall events}

Where the model can be considered most reliable, simulated changes in annual mean rainfall over most of the subcontinent are relatively small compared with corresponding changes in temperature, for example (cf. Joubert, 1994). As a result, the detection of greenhouse-related trends in rainfall in the area through an analysis of changes in long-term means may be difficult. However, given the high sensitivity of the frequency of climatic extremes to even small changes in climatic means and, more particularly, variability (Katz and Brown, 1992), it may be easier to identify a change in climate from an analysis of extreme events. Simulated changes in the magnitude of 10and 30-year flood events are therefore examined. The nature of simulated changes does not appear to differ greatly for other return periods less than 30 years.

Using the GEV distributions fitted to the annual rainfall maxima, changes in daily rainfall associated with return periods of 10 and 30 years were calculated for each grid-point (Figure 5(a) and (b) respectively). The GEV distributions were found to provide significant fits to the annual rainfall maxima over most of the area, except in the north-east, where the model simulation of the annual mean rainfall is poor. The GEV fits were poor also in the tropical latitudes, where the range of annual maxima was large. Widespread increases in daily rainfall maxima are expected for each of the return periods over virtually the entire subcontinent, except for a few localized minima and the western equatorial Indian Ocean. Increases in flood intensities are evident even over the southeastern part of the subcontinent, where decreases in mean annual rainfall were simulated (Figure 4(a)). Although increases are again largest at land-sea boundaries, these are less noticeable than for changes in either the annual mean, the frequency of rain-days, or the intensity of rainfall events (Figure 3). The simulated percentage increases in flood intensity are very similar for the different frequencies of floods considered and are greater than 10 per cent in most areas.

\section{Changes in extreme prolonged rainfall events}

South Africa is regularly affected by extended periods of heavy rainfall often associated with the formation of tropical-temperate troughs (Lindesay and Jury, 1991; Harrison, 1984b). Tropical cyclones such as Domoina and 

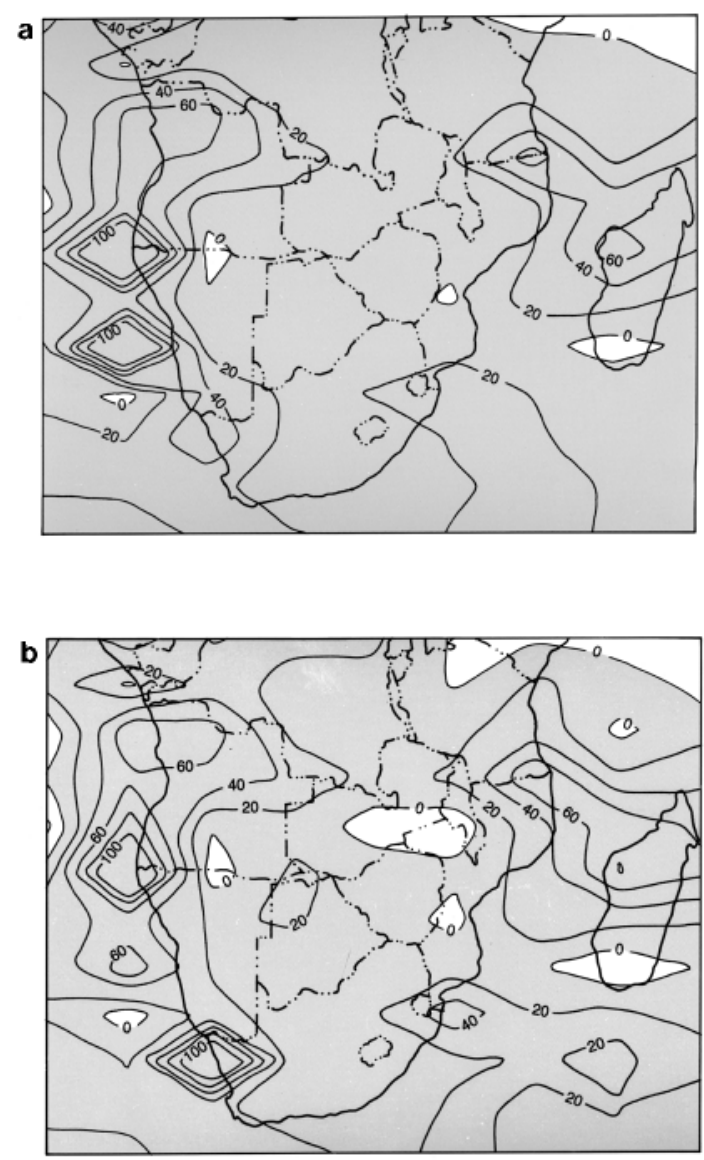

Figure 5. Simulated percentage changes in extreme daily rainfall totals associated with (a) 10- and (b) 30-year return periods. Shading indicates areas of simulated increase in rainfall

Imboa in 1984 are another cause of extended periods of severe flooding, particularly over the east of Natal (Tyson, 1986). The intensity of tropical cyclones may be expected to increase under enhanced greenhouse conditions as a result of warmer sea-surface temperatures (Raper, 1993; Schlesinger, 1993). Prolonged rainfall can have serious implications for flooding and so changes in the intensity of consecutive 5-day (pentad) rainfall extremes are analysed in a manner similar to that adopted for daily rainfall maxima. Changes in extreme pentad rainfall total 10- and 30-year return periods are illustrated in Figure 6. Increases in pentad flood intensities are simulated over most of the subcontinent and the pattern of change is broadly similar to that observed for daily floods (Figure 5).

\section{Discussion}

The pattern of simulated changes in extreme events over southern Africa is more spatially coherent than changes in mean annual rainfall. Similar results from global analyses using the CSIRO4 model (Gordon et al., 1992) and for the Australian region using the CSIRO9 model (Whetton et al., 1993) provide greater confidence in predictions of region-wide changes in extreme rainfall. The implication is that it may be easier to detect evidence for greenhouse-related climatic change through analysing changes in extreme events rather than changes in mean rainfall. However, of more serious concern are the long-term implications of increases in the magnitude and frequency of high rainfall events for flood impacts. For example, the possibility of collapses of small dams and reservoirs is likely to increase and there are up to 100000 people in South Africa that have settled on floodplains which could be inundated (Alexander, 1993). 

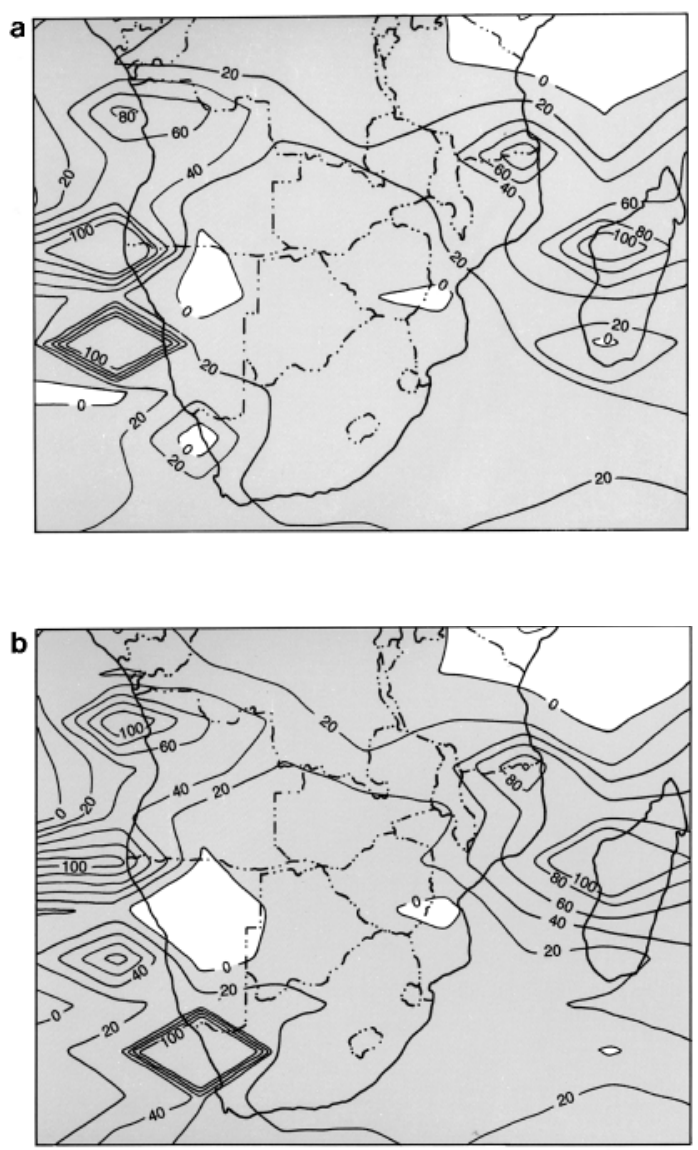

Figure 6. Simulated percentage changes in extreme pentad rainfall totals associated with (a) 10- and (b) 30-year return periods. Shading indicates areas of simulated increase in rainfall

\section{CONCLUSIONS}

The CSIRO nine-level general circulation model simulates widespread increases in mean annual rainfall over much of the southern African subcontinent and surrounding oceanic areas. The pattern of change is not spatially coherent, however, and simulated changes in rainfall are generally largest in areas where the model's control climate performance is poorest. The problem of simulating daily rainfall within a coarse resolution general circulation model is exacerbated in regions of large topographical gradients (at smaller than model grid-scales) that cannot be represented accurately in the model. This is particularly the case with the escarpment region of southern and south-eastern Africa, where the topographical effects are a large determining factor in regional rainfall patterns at daily, monthly and seasonal time-scales (Tyson, 1986).

The model appears to provide clearer predictions of the nature of rainfall changes over both southern Africa and Australia from changes in the frequency and intensity of extreme rainfall events than it does from changes in mean annual rainfall. Both the frequency and intensity of extreme daily and prolonged (pentad) rainfall events increase under doubled- $\mathrm{CO}_{2}$ conditions even in areas where decreases in mean annual rainfall are simulated. Largest increases in the severity of flood events are exhibited over the winter rainfall region. Region-wide increases in flood magnitudes are consistent with theoretical considerations that suggest increases in the magnitude and frequency of extreme rainfall events because the synoptic systems responsible for extreme rainfall, such as tropical cyclones, may be expected to become larger in spatial extent as well as more frequent and more intense (Raper, 1993; Schlesinger, 1993). As a result, throughout the southern African subcontinent the 
early detection of greenhouse-related climatic change may be more evident in changes in the frequency and magnitude of extreme food events than in long-term changes in mean annual rainfall.

\section{ACKNOWLEDGEMENTS}

This research formed part of a Special Programme on South African Climatic Change: Analysis, Interpretation and Modelling (SACCAIM) funded by the Foundation for Research Development. Data for the CSIRO9 model were provided by the Commonwealth Scientific and Industrial Research Organization Division of Atmospheric Research, Mordialloc, Australia. Mr P. Stickler and Mrs W. Phillips drew the diagrams.

\section{REFERENCES}

Alexander, W. J. R. 1993. 'Flood warning systems', S. Afr. Waterbull., 19, 8-10.

D'Abreton, P. C. 1993. 'Water vapour transport over southern Africa during wet and dry early and late summer months', Int. J. Climatol., 13, 151-170.

Fowler, A. M. and Hennessy, K. J. 1995. 'Potential impacts of global warming on the frequency and magnitude of heavy precipitation', Natural Hazards, 11, 283-303.

Gordon, H. B., Whetton, P. H., Pittock, A. B., Fowler, A. M. and Haylock, M. R. 1992. 'Simulated changes in daily rainfall intensity due to the enhanced greenhouse effect: implications for extreme rainfall events', Climate Dyn., 8, 83-102.

Harrison, M. S. J. 1984a. 'A note on the origins of the dry zone of the Limpopo Valley', S. Afr. J. Sci, 80, 333-334.

Harrison, M. S. J. 1984b. 'A generalized classification of South African summer rain-bearing synoptic systems', J. Climatol., 4, 547-560.

Hartmann, D. L. and Michelsen, M. L. 1993. 'Large-scale effects on the regulation of tropical sea surface temperatures', J. Climate, 6, 20492062.

IPCC 1990. Climate Change: the IPCC Scientific Assessment, Houghton, J. T., Jenkins, G. J. and Ephraums, J. J. (eds). Intergovernmental Panel on Climate Change, Cambridge University Press, Cambridge, 365 pp.

IPCC 1992. Climate Change 1992: the Supplementary Report to the IPCC Scientific Assessment, Houghton, J. T., Callander, B. A. and Varney, S. K. (eds), Intergovernmental Panel on Climate Change, Cambridge University Press, Cambridge, 200 pp.

Joubert, A. M. 1994. 'Simulations of southern African climatic change by early-generation general circulation models', Water SA, 20, 315322.

Joubert, A. M. 1995. 'Simulations of southern African climate by early-generation general circulation models', $S A, 91,85-91$.

Joubert, A. M., Mason, S. J. and Galpin, J. S. 1996. 'Droughts over southern Africa in a doubled-CO ${ }_{2}$ climate', Int. J. Climatol., 16, in press.

Katz, R. W. and Acero, J. G. 1994. 'Sensitivity analysis of extreme precipitation events', Int. J. Climatol., 11, $505-513$.

Katz. R. W. and Brown, B. G. 1992. 'Extreme events in a changing climate: variability is more important than averages', Clim. Change, 21, 289-302.

Lindesay, J. A. and Jury, M. R. 1991. 'Atmospheric circulation controls and characteristics of a flood event in central South Africa', Int. J. Climatol. 11, 609-627.

Mason, S. J. 1995. 'Climatic change over the Lowveld of South Africa', Clim. Change, 32, 35-54.

Mason, S. J. and Mimmack, G. M. 1995. 'Changes in flood frequencies in South Africa', Preprints of the Sixth International Meeting on Statistical Climatology, University College, Galway, 295-298.

McGregor, J. L., Gordon, H. B., Watterson, I. G. and Dix, M. R. 1993. 'The CSIRO 9-level Atmospheric General Circulation Model', CSIRO Division Atmospheric Research Technical Paper, No. 26, CSIRO, Melbourne, 89 pp.

Mearns, L. O., Katz, R. W. and Schneider, S. H. 1984. 'Extreme high-temperature events: changes in their probabilities with changes in mean temperature', J. Clim. Appl. Meteorol., 23, 1601-1613.

Mearns, L. O., Schneider, S. H., Thompson, S. L. and McDaniel, L. R. 1990. 'Analysis of climate variability in general circulation models: comparison with observations and changes in variability in $2 \times \mathrm{CO}_{2}$ ', J. Geophys. Res., 95, 20469-20490.

Mitchell, J. F. B. and Ingram, W. J. 1992. 'Carbon dioxide and climate: mechanisms of changes in cloud', J. Climate, 5, 5-21.

Nicholson, S. E., Kim, J. and Hoopingarner, J. 1988. Atlas of African Rainfall Variability, Department of Meteorology, The Florida State University, Tallahassee, FL. 237 pp.

Noda, A. and Tokioka, T. 1989. 'The effect of doubling the $\mathrm{CO}_{2}$ concentration on convective and non-convective precipitation in a general circulation model coupled with a simple mixed layer ocean model', J. Meteorol. Soc. Jpn, 67, 1057-1069.

Pittock, A. B. 1994. 'A climate change perspective on grasslands', Proceedings, XVII International Grasslands Congress, February 1993, Massey University, Palmerston North, New Zealand.

Raper, S. C. B. 1993. 'Observational data on the relationships between climatic change and the frequency and magnitude of severe tropical storms', in Warrick, R. A., Barrow, E. M. and Wigley, T. M. L. (eds), Climate and Sea Level Change: Observations, Projections and Implications, Cambridge University Press, Cambridge, 424 pp.

Rind, D., Goldberg, R. and Ruedy, R. 1989. 'Change in climate variability in the 21st century', Climate Change, 14, 5-37.

Rohatgi, V. K. 1976. An Introduction to Probability Theory and Mathematical Statistics, Wiley, New York, 684 pp.

Schlesinger, M. E. 1993. 'Model projections of $\mathrm{CO}_{2}$-induced equilibrium climate change', in Warrick, R. A., Barrow, E. M. and Wigley, T. M. L. (eds), Climate and Sea Level Change; Observations, Projections and Implications, Cambridge University Press, Cambridge, 424 pp.

Schulze, B. R. 1984. Climate of South Africa: Part 8: General Survey, WB28, South African Weather Bureau, 5th edn., 330 pp.

Stephens, G. L. 1990. 'On the relationship between water vapour over the oceans and sea surface temperature', J. Climate, 3, $634-645$.

Trenberth, K. E. 1991. 'General characteristics of El Niño-Southern Oscillation', in Glantz, M. H., Katz, R. W. and Nicholls, N. (eds), Teleconnections Linking Worldwide Climate Anomalies, Cambridge University Press, Cambridge, 535 pp. 
Triegaardt, D. O., Terblanche, D. E., van Heerden, J. and Laing, M. V. 1988. The Natal Flood of 1987, South African Weather Bureau Technical Paper No. 19, Pretoria, 62 pp.

Tyson, P. D. 1986. Climatic Change and Variability in Southern Africa, Oxford University Press, Cape Town, 220 pp.

Vogel, C. H. and Drummond, J. 1993. 'Dimensions of drought: South African case studies', Geojournal, 30, 93-98.

Whetton, P. H., Fowler, A. M., Haylock, M. R. and Pittock, A. B. 1993. 'Implications of climate change due to the enhanced greenhouse effect on floods and droughts in Australia', Clim. Change, 25, 289-318.

Wigley, T. M. L. 1987. 'Impact of extreme events', Nature, 316, 106-107.

Wigley, T. M. L., and Jones, P. D. 1987. 'England and Wales precipitation: a discussion of recent changes in variability and an update to 1985', J. Climatol, 7, 231-246.

Wilson, C. A. and Mitchell, J. F. B. 1987. 'Simulated $\mathrm{CO}_{2}$ induced climate change over western Europe', Clim. Change, 10, 11-42.

Zhang, C. 1993. 'Large-scale variability of atmospheric deep convection in relation to sea surface temperature in the tropics', 10, J. Climate, $1898-1913$. 